\title{
RETRATO DE UM BRASIL: VIOLÊNCIA ESTRUTURAL NAS QUESTÕES DO CAMPO
}

PORTRAIT OF A BRAZIL: STRUCTURAL VIOLENCE IN LAND ISSUES

\author{
${ }^{1}$ Fabiana Ferreira Novaes \\ ${ }^{2}$ Daniel Gonçalves de Oliveira
}

\section{RESUMO}

Mesmo com governos que se mostraram inicialmente conciliadores de classes, não houve avanço nos processos de regularização fundiária e promessas de Reforma Agrária no Brasil. Constata-se a reprodução de uma violência sistêmica crescente, com a omissão do próprio Estado contribuindo para sua perpetuação. Por outro lado, a sociedade em geral compreende a luta pela terra como indevida e enxerga os sujeitos sociais envolvidos como não merecedores de direitos. Este fator encontra explicação no engessamento de uma sociedade com estruturas hierárquicas. A tal pensamento soma-se a flexibilização das violações de direitos conquistados sob a justificativa de necessário gerenciamento de crises incontornáveis.

Palavras-chave: Reforma agrária, Violência estruturante, Violações de direitos, Questões do campo, Políticas publicas

\begin{abstract}
Even with governments that started as class conciliators, there was no progress in land regularization process and promises of agrarian reform in Brazil. It is noticed a growing systemic violence, with the omission of the State itself contributing to its perpetuation. On the other hand, society in general understands the struggle for land as improper and sees social subjects involved as undeserving of rights. This factor is explained by the inflexibility of a society with hierarchical structures. This thought adds to the flexibility of conquered rights violations on the grounds of necessary management compelling crises.
\end{abstract}

Keywords: Land reform, Structuring violence, Rights violations, Agrarian issues, Public policy

\footnotetext{
1 Mestranda em Direito Agrário pela Universidade Federal de Goiás - UFG, Goiás (Brasil). E-mail: fanovaes@ymail.com

2 Mestrando em Direito Agrário pela Universidade Federal de Goiás - UFG, Goiás (Brasil). E-mail: suprvdaniel@gmail.com
} 
A Fala da Terra

A Liberdade da Terra não é assunto de lavradores. A liberdade da Terra é assunto de todos quantos se alimentam dos frutos da terra. Do que vive, sobrevive de salário. Do que não tem casa. Do só tem o viaduto. Dos que disputam com os ratos os restos das grandes cidades.

Das meninas e meninos de rua.

Das prostitutas. Dos ameaçados pela Cólera.

Dos que amargam o desemprego.

Dos que recusam a morte do sonho.

A Liberdade da Terra e a paz no campo tem nome: Reforma Agrária.

Hoje viemos cantar no coração da cidade.

Para que ela ouça nossas canções e cante.

E reacenda nesta noite a estrela de cada um.

E ensine aos organizadores da morte

e ensine aos assalariados da morte

que um povo não se mata

como não se mata o mar

sonho não se mata

como não se mata o mar

a alegria não se mata

como não se mata o mar

a esperança não se mata

como não se mata o mar

e sua dança.

Pedro Tierra (Epílogo do Livro Conflitos Agrários, seus sujeitos, seus direitos, pg. 08)

\section{INTRODUÇÃO}

De início tomamos uma proposição usada pela filósofa brasileira Marilena Chaui desde os anos 80, acerca da estrutura da nossa sociedade, hierarquizada, marcada por violência e autoritarismo. Características que vão de encontro à imagem cultural de uma nação que se define por cordial, acolhedora e propagadora da reciprocidade. Em geral essa é a imagem presente no ideário do brasileiro quando fala de si mesmo, contudo, ao considerar o conjunto (o brasileiro enquanto sociedade), falta o rigor de um olhar bem mais crítico. $\mathrm{O}$ cotidiano da sociedade camufla relações de poder que se reproduzem historicamente na vida 
pública, no aparato estatal e na vida social, no entanto é como se tais relações (camufladas) não existissem.

Nesse sentido Chaui nos chama a atenção para a violência generalizada, presente em toda a sociedade brasileira, como algo estrutural. Não se tratam de violências pontuais, mas de um comportamento aceito, reproduzido e tido como aceitável, comum. Significa dizer que direitos há muito conquistados são continuamente violados todos os dias, sem que haja reação contrária. Ocorrida determinada violação, a mídia veicula como algo que deveria mesmo ser feito e a sociedade concorda e corrobora que é (um mal) necessário. Essa lógica - ou falta de não poderia ser mais escancarada que no caso da luta pela terra, em todos os seus aspectos. Seja do ponto de vista do camponês, do pequeno produtor, dos sem terra, dos índios, ribeirinhos, quilombolas, seringueiros etc., ainda que haja direito expresso de acesso a terra, a luta para que tais direitos sejam efetivados é tida como algo absurdamente errado. Assim essas minorias têm a efetivação de seus direitos negada, permanecendo invisíveis às instituições públicas, reprimidos pela polícia, criminalizados pelo judiciário, sentenciados pela mídia e marginalizados da sociedade. Trata-se então de uma violência geral, que abrange toda a estrutura social no Brasil, estendendo-se ao campo.

Nesse panorama, a presença histórica de minorias e movimentos sociais que se insurgem como importantes atores de resistência dá origem aos diversos conflitos sobre a terra. Pois cada vez mais conscientes dos próprios direitos, reconhecidos, estes grupos reivindicam que o poder público cumpra com o seu dever. Apesar disso, as luta e contestações em face da violência e negação de direitos são propaladas no consciente coletivo como "crises", "revoltas" e indignações infundadas a serem contornadas. Conceito que nesse contexto tem a intenção de justificar a ocorrência de violações que o Estado Democrático de Direito não permitiria, sendo próprias de um estado de exceção (Agamben, 2013). Assim, sob o pretexto de crise, a violência se legitima e a normalidade passa a ser o estado de exceção permanente.

Partindo dessas ideias, este artigo pretende dialogar sobre o impacto da violência estrutural nas questões do campo, especialmente sobre a Reforma Agrária e seu desdobramento em regularização fundiária e políticas públicas. Ou seja, se há o direito, e reconhecimento legal do direito, o que impede sua efetivação (regularização e promoção de política pública)? Parece-nos claro, conforme incentiva o pensamento de Chaui, que na lacuna entre direito conquistado e direito efetivo, reside de forma petrificada a base de uma 
sociedade conservadora, hierárquica, favorável à defesa de privilégios e não de direitos. Uma sociedade oligárquica.

\section{O CONTEXTO HISTÓRICO}

A história da luta por terras e territórios no Brasil, convive desde o seu primórdio com a transgressão dos direitos territoriais e a violência contra as minorias sociais e étnicoraciais como índios, quilombolas, camponeses dos movimentos da reforma agrária, seringueiros, pescadores artesanais e vários outros. A bem da verdade, a história dos conflitos no campo renova-se incessantemente e parece que jamais terá fim e assim reflete a própria história brasileira:

$\mathrm{Na}$ verdade, a história da sociedade brasileira tem sido uma história inacabada, uma história que não se conclui, uma história que não chega ao fim de períodos definidos, de transformações concluídas. Não é uma história que se faz. É uma história sempre por fazer. (MARTINS, 1994, p. 11).

Nesse sentido, faz-se necessário, para compreender a relação de dominação e subjugação que há na estrutura fundiária brasileira, considerar a realidade paradoxal que nos persegue: a terra como mercadoria versus a terra como provedora de vida:

A cultura proprietária moderna e capitalista entende a terra como mercadoria e para que seja uma efetiva mercadoria deve estar vazia. Tudo o que tornar a terra permanentemente ocupada, como a natureza animal e vegetal, os índios e as populações tradicionais, são obstáculos para o exercício do direito de propriedade e considerado entrave ao livre desenvolvimento capitalista. (SOUZA FILHO, 2015, p. 57)

O cenário histórico vicioso que acompanha a questão fundiária brasileira nasce antes mesmo do próprio Estado-Nação, sendo anterior a chegada dos portugueses às terras do Atlântico Sul, pois à época Portugal e Espanha disputavam a hegemonia dos mares no intuito de expandir seu domínio territorial. Com a chegada de Colombo ao que chamaram de Novo Mundo, Portugal ressentido contesta as pretensões da Espanha, todavia, o entrave intermediado pelo papa Alexandre VI resolveu-se com a edição do que hoje conhecemos como Tratado de Tordesilhas em 1494, que delimitava a quem cabia a terra descoberta e aquelas por descobrir.

Do ponto de vista jurídico, as terras que hoje se reconhecem como sendo o Estado brasileiro, ao leste eram de Portugal e ao oeste da Espanha, ou seja, desde 1494 as terras brasileiras não pertenciam mais aos seus nativos. Juridicamente desconsiderados e 
posteriormente subjugados e expropriados, os nativos, que passaram a ser chamados genericamente de índios, perderam suas terras, seus nomes, suas línguas, seus cantos, seus risos e sonhos de viver em paz.

Transcorridos séculos desde o primeiro ato jurídico que formalizou a violência e inaugurou o conflito fundiário no Brasil, a realidade não é tão outra assim. Apesar de haverem direitos nas Constituições e nos Tratados, que por vezes parecem marionetes nas mãos de juristas que reproduzem um sistema viciado, (re)inventando teses jurídicas que acabam por vilipendiar os indígenas mais uma vez a despeito do reconhecimento literal na Carta Magna, não apenas esses, mas também os quilombolas (fruto da expatriação escravocrata), os camponeses e as populações tradicionais (fruto da desigualdade social histórica e sistêmica).

As lutas sempre existiram, mas quase sempre desmanteladas em prol da "ordem pública" e criminalizadas pela mesma ordem jurídica que formaliza a subjugação dos pequenos pelos grandes. Esse contexto histórico se repete e se replica desde sempre, a questão fundiária brasileira pertence a um círculo vicioso, sem apresentar possibilidade de mudança em sua estrutura nem mesmo nos governos ditos à esquerda do espectro político, que se ergueram inclusive, apoiados pelos movimentos sociais que lutam por acesso e permanência na terra.

Desde a colonização do Brasil o regime jurídico de regulação das relações dos indivíduos com a terra, salvo pontuais e marginais exceções, alinhava-se com o modelo social hegemônico para desenvolver suas atividades econômicas e perpetuar a estrutura colonizadora e de acúmulo estabelecida inicialmente. Nesse modelo, em suas dimensões coletivas ou individuais, sujeitos que estivessem em desacordo com o sistema de produção hegemônico, desde sempre tiveram pouca ou nenhuma possibilidade de utilizar o sistema jurídico do Estado para garantir acesso a terra e viabilizar uma vida com dignidade, segundo seus padrões culturais (MARÉS, 2003).

Ressalta-se que, no contexto de negação dos direitos territoriais e disputa territorial, a visão da terra como bem produção sempre se opõe as formas coletivas de sua ocupação e uso. Logo, nesse compasso, as propriedades comuns foram e são consideradas "bens de mãos mortas", improdutivas, logo deveriam (e ainda deverão) ser melhor aproveitadas por sistemas de produção alinhados com o direcionamento político e econômico (nesse caso mais econômico do que político), sendo assim o que é óbice à produtividade deve ser desconsiderado e lançado fora. (ZIBETTI, 2005) 
Por tanto, forçoso é de se concluir que a transgressão de direitos e a violência são intrínsecas a questão fundiária, formando juntamente com outros inúmeros fatores ao longo do tempo, uma estrutura perversa que insiste em se eternizar.

\section{NÚMEROS DA REFORMA: NÃO REGULARIZAÇÃO E VIOLÊNCIA NO CAMPO}

A partir do contexto histórico, percebe-se que a violência estrutural presente na questão fundiária brasileira rompe os séculos e se atualiza sempre impiedosa. Na edição 2015 da publicação da Pastoral da Terra - Conflitos no Campo Brasil, o geógrafo Ariovaldo Umbelino de Oliveira incita à reflexão sobre o aumento da violência no campo.

Segundo Oliveira (2016), a realização da reforma agrária já não está na pauta do governo há muito tempo, mesmo sendo preceito de ordem constitucional e, por conseguinte, "obrigação do governo em fazê-la, e, direito dos cidadãos em tê-la" (p. 29), inclusive o autor aponta para o descumprimento contínuo da legislação brasileira por parte dos governos na elaboração do Plano Nacional de Reforma Agrária, apontando que desde a previsão legal no Estatuto da Terra em 1964, o dito plano foi elaborado "apenas duas vezes, no governo Sarney o primeiro e no primeiro mandato de Lula o segundo" (p. 29), reafirmando a urgência, necessidade e obrigatoriedade do governo atual em fazê-la.

Observa-se que o Plano Nacional de Reforma Agrária - PNRA, que consta no Capítulo IV do Estatuto da Terra, trata-se de um planejamento estratégico para execução da reforma agrária no que tange ao acesso e à permanência na terra, incluindo medidas prioritárias nas áreas de saneamento, educação e assistência técnica às famílias beneficiadas.

Nessa análise, conclui-se, também, que garantir apenas o acesso a terra não é suficiente para consolidar a reforma agrária e combater a violência que decorre de sua não realização, é preciso garantir à permanência mediante implantação e execução de políticas públicas que forneçam condições de vida digna para a população no campo, para que nele possam permanecer com esperanças, viver dignamente, produzir de forma sustentável e sonhar incondicionalmente.

Como dizia Carlos Drummond de Andrade, "As leis não bastam. Os lírios não nascem das leis", haja vista que a realidade experimentada pelos protagonistas das lutas por terra em face da velha estrutura fundiária brasileira está distante da efetividade das leis postas e vigentes no ordenamento jurídico.

Os números da violência atordoam ainda mais as utopias de dias melhores e fazem experimentar a amargura da realidade do campo, onde os conflitos se intensificam por vários 
fatores: desinteresse do Estado em promover a reforma agrária; em reconhecer e efetivar os direitos territoriais dos povos indígenas, de quilombolas e outras populações tradicionais; corrupção nos órgãos executores; avanço do latifúndio e dos empreendimentos do agronegócio; ausência de políticas públicas para o campo, especialmente aquelas de infraestrutura básica (saúde, educação, saneamento) e de desenvolvimento voltadas a estas comunidades. Em suma, a violência é alimentada pela visão antagônica da terra (mercadoria versus provedora de vida).

Oliveira (2016), desnuda em números a realidade e a violência dos conflitos no campo no ano de 2015 que registrou um aumento de 39\% no número de assassinatos em comparação com o ano de 2014, mesmo o número de ocorrências de conflitos sendo menor em 2015 do que em 2014, o que esboça o acirramento dos conflitos, não de forma quantitativa, mas qualitativa, conforme os dados apresentados pelo autor.

Os dados de 2015 apresentados na mais recente publicação da Comissão Pastoral da Terra (CPT), no mesmo sentido revelam a redução dos conflitos em números de ocorrências, porém o aumento preocupante do número de vítimas. Isso, de certa forma expressa quem está vencendo a luta por direitos no campo. E, não é só o embate direto que contribui para a violência, a falta de assistência aos camponeses, inclusive aqueles que já estão assentados por exemplo, só agrava a problemática da violência e marginalização.

\subsection{Políticas Públicas}

Retomando o que fora dito anteriormente, a reforma agrária não está restrita tão somente a promoção de uma melhor e justa distribuição de terras e/ou dar novos contornos à estrutura fundiária, de modo a evitar a concentração de terras nas mãos de uns poucos e, por conseguinte, a formação de latifúndios improdutivos e injustos. A reforma é também uma política pública social, hábil a promover o desenvolvimento econômico e social no meio rural, com vistas a reduzir a pobreza, as desigualdades regionais, o êxodo rural e a violência estrutural que persiste no espaço agrário brasileiro.

Segundo informações constantes do sítio eletrônico do Instituito Nacional de Colonização de Reforma Agrária (INCRA), "A Reforma Agrária é um conjunto de medidas para promover uma melhor distribuição da terra mediante modificações no regime de posse e uso" objetivando cumprir com a justiça social, com o desenvolvimento rural sustentável e o aumento da produção, conforme imperativos do Estatuto da Terra. ${ }^{1}$

Nesta diretiva, segundo o INCRA, a reforma agrária deve proporcionar dentre outros: 
desconcentração e democratização da estrutura fundiária; produção de alimentos básicos; geração de ocupação e renda; combate à fome e à miséria; interiorização dos serviços públicos básicos; redução da migração campo-cidade; promoção da cidadania e da justiça social; diversificação do comércio e dos serviços no meio rural e; democratização das estruturas do poder. E ainda: para os já beneficiários da reforma agrária, ou melhor, já assentados, o INCRA deve promover igualdade de gênero na reforma agrária, além do direito à educação, à cultura e à seguridade social, dentre outros. Tudo isso deveria na prática se materializar por meio das políticas públicas.

No entanto, o que se nota nos assentamentos já estabelecidos é a espera por serviços essenciais que garantam o mínimo existencial e condições de vida digna. O que evidencia não só a violação ao direito de ter acesso a terra, mas tendo acesso a ela também de nela permanecer e viver.

O modelo de reforma agrária brasileira, distante das diretrizes que estão no papel, está longe de cumprir efetivamente com o que o próprio Estado diz entender por reforma agrária, o que acaba por corroborar com a intensificação e manutenção da violência como um pressuposto da luta pela reordenação territorial no país.

A negligência por parte dos governos, não só pra promover o acesso a terra, mas também, em propiciar aos camponeses assentados condições de viver na terra e da terra, configura uma ofensa aos preceitos constitucionais de forma escancarada e vergonhosa. E, ainda sob análise, no que tange às políticas públicas de acesso e permanência na terra para os camponeses, discute-se nesse ínterim a política agrícola com todos os seus pressupostos básicos elencados pela Carta Magna, inclusive, em conformidade com o que preconiza o $\S 2^{\circ}$ de seu artigo 187.

\footnotetext{
Art. 187. A política agrícola será planejada e executada na forma da lei, com a participação efetiva do setor de produção, envolvendo produtores e trabalhadores rurais, bem como dos setores de comercialização, de armazenamento e de transportes, levando em conta, especialmente:

I - os instrumentos creditícios e fiscais;

II - os preços compatíveis com os custos de produção e a garantia de comercialização;

III - o incentivo à pesquisa e à tecnologia;

IV - a assistência técnica e extensão rural;

V - o seguro agrícola;

VI - o cooperativismo;

VII - a eletrificação rural e irrigação;
}

\footnotetext{
${ }^{1}$ Disponível em <http://www.incra.gov.br/reformaagraria> acesso em 24 maio de 2016.
} 


\section{VIII - a habitação para o trabalhador rural.}

$\S 1^{\circ}$ Incluem-se no planejamento agrícola as atividades agroindustriais, agropecuárias, pesqueiras e florestais.

$\$ 2^{\circ}$ Serão compatibilizadas as ações de política agrícola e de reforma agrária. (Grifamos)

Para evidenciar a inabilidade de promoção de acesso e permanência na terra e acirramento dos conflitos por ausência de políticas públicas, traz-se de forma breve e instrumental o comentário sobre projetos de assentamentos no município de Ribeirão Cascalheira, na região conhecida como Vale do Araguaia, no estado do Mato Grosso: Em 2009, o INCRA por intermédio da Presidência da República, oficializou via decreto um dos vários projetos existentes naquela municipalidade, o Assentamento Santa Rita, que segundo informações de 2009 detinha capacidade para assentar 570 famílias.

Importante destacar que a ocupação da área que corresponde ao Assentamento Santa Rita é anterior a sua "criação" legal em 2009, porém, mais de seis anos após a oficialização desse projeto e quase 10 anos de efetiva ocupação, o que se vê no assentamento é a falta de infraestrutura básica para os assentados, que carecem de energia elétrica, de financiamento, saúde, educação e saneamento.

Mesmo que sumário, o exemplo do Assentamento Santa Rita demostra claramente que a falta de assistência e de condições básicas para sobreviver, deságua em duas contradições à reforma agrária: o abandono das parcelas pelos assentados e o surgimento de conflitos internos. E não se trata de um caso isolado. Reflete o descaso dos governos com a reforma agrária e com a promoção da política agrícola para os assentados, reforçando a violência mesmo após o acesso a terra, pois o foco da luta passa a ser a permanência e sobrevivência em uma estrutura indigna para com os camponeses.

Nesse mesmo sentido também comunidades que não sejam necessariamente de camponeses, como as tradicionais, quilombolas, indígenas e outras, apesar de terem diretrizes específicas e diferenciadas, para terem acesso às respectivas políticas públicas dependem antes do acesso a terra. No caso de comunidades quilombolas, para consolidação da política de Estado (Agenda Social Quilombola - Decreto 6262/2007) agrupam-se vários ministérios nos eixos Acesso a Terra; Infraestrutura e Qualidade de Vida; Inclusão Produtiva e Desenvolvimento Local; e Direitos e Cidadania. Contudo, para que se deem o segundo, terceiro e quarto se faz necessário antes o acesso regulamentado, seja pelo INCRA quando de sua responsabilidade; pela Secretaria de Patrimônio da União (SPU, também responsável por expedir título ou Contrato de Concessão de Direito Real de Uso - CCDRU, às comunidades 
quilombolas localizadas em áreas de sua gestão) ou pelos Estados e Municípios (aos quais cabe expedir os títulos às comunidades quilombolas que se localizam em terras de domínio estaduais e municipais). ${ }^{2}$

Da mesma forma no que toca às comunidades indígenas. A demarcação, de competência do Ministério da Justiça por meio da Funai, é primordial para a efetivação do direito de acesso por meio da demarcação e para permitir a reprodução dos seus modos de vida e relação com a terra. Portanto, o reconhecimento, a segurança territorial em terras indígenas, a redução de conflitos (reassentando ocupantes não indígenas, bem como indenizando benfeitorias etc.) não pode se dar sem a ação primeira da demarcação das terras.

Como fica demonstrado, todo tipo de políticas complementares ao direito de acesso à terra passa sempre pelo reconhecimento e regularização dessa terra. Conclusivo, que a insistência em não redistribuir o espaço rural e opção em manter as estruturas oligárquicas no campo desfavorece a resolução de conflitos (ao contrário, os instiga), bem como a regularização necessária à efetivação dos direitos que dela decorrem. Desse modo, estabelecem-se limitações ao desenvolvimento social destes grupos e barreiras à sua economia particular. Essa triste realidade se renova constantemente, de forma cíclica e viciosa, trazendo à tona a estrutura violenta e de mudança letárgica. Violenta não apenas do ponto de vista de resolução dos conflitos, mas também no que se refere à sonegação dos direitos previstos para os camponeses por parte do Estado.

Assim, a justa distribuição de terras por meio da reforma agrária reivindicada historicamente e marcada pela tradição dos conflitos, nunca se concretiza e a regra, o habitual, se torna a negação da justiça social. A reforma agrária no Brasil se mostra abstracionista, dominada pelos adornos por vezes incompreensíveis, da aparência insensível e imaterial de sua realidade prática.

\footnotetext{
${ }^{2}$ Disponível em <http://www.incra.gov.br/sites/default/files/incra-perguntasrespostas-a4.pdf > acesso em 24 maio de 2016.
} 


\section{REDUCIONISMO DA DEMOCRACIA E LEGITIMAÇÃO PELA EXCEÇÃO}

Na sociedade brasileira a compreensão de cidadania se deu no contexto original em que o senhor de escravos (cidadão) é um indivíduo com privilégios de classe e o exercício da cidadania integrava esse privilégio. A permissão de acesso pelas demais classes a esse exercício dependia da vontade dos senhores em conceder ou não, podendo inclusive retirá-lo mesmo depois de concedido (CHAUI, 2008) conforme seu interesse. Trata-se historicamente de uma sociedade organizada em classes e da perpetuação dessa lógica, que se reproduz em relações de hierarquia. Nesse sentido, "as diferenças e assimetrias sociais e pessoais são imediatamente transformadas em desigualdades" (CHAUI, 2008, p. 70) de modo que aspectos essenciais ao que denominamos Democracia são postos de lado, vez que os sujeitos nessa relação não são vistos como iguais, autônomos e portadores dos mesmos direitos. A título de exemplo, a ideia de igualdade tanto repetida nos nossos discursos democráticos carece ainda de profundidade de reflexão e não simples propagação rasa, pois o conceito de isonomia vai muito além:

[...] todos são iguais porque livres, isto é, ninguém está sob o poder de um outro porque todos obedecem às mesmas leis das quais todos são autores (autores diretamente, numa democracia participativa; indiretamente, numa democracia representativa). Grifo nosso (CHAUI, 2008, p. 67).

Nessa perspectiva um dos grandes desafios da democracia em uma sociedade de classes é, em face da desigualdade real, manter e defender os próprios princípios democráticos. O seu reducionismo, segundo Chaui, é hábito herdado do pensamento liberal para o qual democracia se trata de "regime de lei e da ordem para a garantia das liberdades individuais" (2008, p. 66). Porém, nesse pensamento a noção de liberdade está identificada com a de competição, livre iniciativa, concorrência. Ainda outra identificação relevante é a da ordem com a força dos poderes (executivo e judiciário) a fim de impedir o desenvolvimento de conflitos e embates sociais por meio da repressão. O aminguamento das ideias e práticas democráticas compacta a Democracia deixando de perceber uma profundidade ideológica que deveria estar ampliada como forma de sociedade e não simples regime político que determina uma forma de governo, com soluções técnicas para problemas sociais.

Nesse contexto hierarquizado, sob influencias do paternalismo e do clientelismo histórico somado às concepções liberais que a sociedade brasileira incorpora, as relações entre 
Estado e cidadão são tidas como favor, benesse concedida e tomam forma de dependência. "É exatamente isso que faz a violência ser a regra da vida social [...]” (p. 70) já que as leis passam a ser instrumento, por um lado de manutenção de privilégios e por outro de repressão e exclusão, a exemplo dos direitos reconhecidos e nunca efetivados como os aqui debatidos.

Essa exclusão e a perpetuação da violência se legitimam a contrassenso da democracia, a partir da própria representação política desde seu processo de feitura de leis (no qual os integrantes do Poder Legislativo deveriam representar toda a sociedade), bem como no seu cumprimento (pelo Executivo) e na garantia de direitos (pelo Judiciário). Desse modo, à margem da representação desenvolvem-se os movimentos sociais a fim de reivindicar direitos e pressionar o Estado para a sua efetivação. Todavia, mesmo diante de alguma participação popular, não se pode perder de vista que na sociedade oligárquica a reivindicação não significa direito efetivado e a indignação popular é considerada um transtorno, desordem, uma crise a ser administrada. Nessa acepção afirma Chaui que "cada vez que há uma luta por direitos contra privilégios, essa luta é vista como violenta e precisa ser reprimida. Há, portanto, uma inversão ideológica fantástica no Brasil: a violência é vista como ordem" 3 .

Concomitantemente a mesma "crise" se torna justificativa para que governos primeiro: deixem de realizar suas ações prioritárias como investimento em saúde, educação e há décadas a reforma agrária (para citar alguns), a pretexto de que se deve antes resolver alguma crise do momento; e em segundo, permite a violação de direitos sob a alegação de que em tempos de exceção a limitação ou mesmo inviabilização total de alguns direitos é plausível e admissível.

Neste ponto, o entendimento singular que traz o filósofo e jurista italiano Giorgio Agamben em suas considerações sobre um novo padrão de atuação dos Estados diante do que rotulam como crises ou situações de risco, é extremamente importante na construção do diálogo aqui proposto. O filósofo identifica um movimento internacional de criação de medidas e procedimentos extrajudiciais e judiciais que visam restringir direitos a fim de manter a ordem na sociedade. $\mathrm{O}$ estado de exceção permanente configura o que ele chama de totalitarismo moderno: a "instauração [...] de uma guerra civil legal que permite a eliminação física não só dos adversários políticos, mas também de categorias inteiras de cidadãos que, por qualquer razão permaneçam não integráveis ao sistema político” (AGAMBEN, 2004, p.

\footnotetext{
${ }^{3}$ Sociedade brasileira: violência e autoritarismo por todos os lados. Marilena Chaui em entrevista concedida à revista Cult disponível em http://revistacult.uol.com.br/home/2016/02/sociedade-brasileira-violencia-eautoritarismo-por-todos-os-lados/.
} 
13). Segundo esta percepção o conceito de "crise" se transformou em instrumento de dominação, tornando-se o mote da política moderna e integrando a vida social em seus mais variados aspectos. "Ela serve para legitimar decisões políticas e econômicas que de fato desapropriam cidadãos e os desproveem de qualquer possibilidade de decisão" ${ }^{4}$ e mais: em caráter duradouro. Ou seja, a incerteza afirmada pela crise se prolonga para um futuro indeterminado, ao infinito. Em geral não se cogita possibilidade de resolução, pois na lógica de usá-la como justificativa, o adiamento repetitivo produz melhor resultado. Nesse sentido a crise interminável, bem como um estado de emergência, é incompatível com a democracia ${ }^{5}$. Por meio desta prerrogativa se propagam decisões políticas que seriam consideradas absurdas em outras circunstâncias, surgindo todo tipo de intervenções violentas e restrição de direitos dos cidadãos sob a explicativa de proteger o mesmo cidadão.

No caso da sociedade brasileira, trazer este entendimento é esclarecedor à interpretação de nossas conjunturas sociais e políticas em geral. Também com relação aos conflitos no campo, significa dizer que se retifica a lógica (já existente) de adiamento reiterado do caos fundiário e inexistência de qualquer possibilidade de fim ou resolução do conflito. "Junto com a crise, a justificativa para a não realização da Reforma Agrária passou a ser a falta de recursos financeiros. Mas a verdade é que ela já não é prioridade de governo há muito tempo" (OLIVEIRA, 2016, p. 1).

Como se sabe, é de conhecimento público o histórico violento da luta por terras no Brasil, os próprios dados do INCRA demonstram a redução gradativa dos assentamentos realizados nos últimos anos, observado o panorama geral. Em paralelo a Comissão Pastoral da Terra vem constantemente realizando denúncias da violência, a exemplo de sua ultima publicação sobre a situação de conflitos na Amazônia, revelando que dos 51 assassinatos registrados no Brasil nesse contexto em 2015, 48 foram na Amazônia (21 só no estado de Rondônia). Diante desse quadro de violência estruturante que alcança a luta pela terra, a omissão do poder público e indiferença da sociedade dão-se as mãos, selando a guerra no campo.

\footnotetext{
${ }^{4}$ Ibidem.

5 Ibidem
} 


\section{CONCLUSÃO}

Apesar do reconhecimento do direito a terra e da obrigação do Estado em realizar a Reforma Agrária, o ranço do comportamento disseminado no Brasil desde a Coroa portuguesa, posteriormente perpetuado nas capitanias e pelo coronelismo, se estende até a República fazendo-se presente nos dias atuais ao passo que a luta das minorias no campo contínua invisível e marginalizada. O ponto central do conflito por terras no Brasil tem, desde o início, a sede por acúmulo e o acúmulo por espoliação.

Esse modo de operar social - Coroa versus não gente (índios) e senhor versus escravo (negros) já era em sua origem uma violência extrema. De forma que o objetivo da disputa por terras brasileiras foi (inicialmente entre as coroas portuguesa e espanhola), como ainda é (entre os atores do latifúndio), a concentração em si mesma e a máxima exclusão dos 'não cidadãos'. É indiscutível que a reprodução histórica da violência fundiária brasileira se assenta sobre as bases estruturais pautadas na expropriação e concentração de terras, atualmente mantida em nome de um dito "desenvolvimento" que tem por vetor o agronegócio latifundiário.

Insta destacar, que todos os poderes do Estado operam contra a redistribuição igualitária de terras no Brasil. Se de um lado o Executivo é letárgico para promover a Reforma Agrária e/ou a regularização fundiária dos territórios indígenas, quilombolas e das demais comunidades tradicionais, e, também, tornar efetivas políticas públicas hábeis a desenvolver e propiciar condições de vida digna aos mesmos. Do outro lado, o Legislativo sempre se insurge com propostas para modificar, dificultar, obstruir, retirar, sonegar, vilipendiar e todos os outros verbos que possam indicar a atuação contrária ao reconhecimento dos direitos territoriais e sociais dos camponeses e das minorias étnico-raciais que clamam por redistribuição ou regularização das terras. O Judiciário tende a distorcer o sentido original das leis, e desempenha uma interpretação duramente tradicionalista a fim de proteger a propriedade privada que avança sobre as terras indígenas, quilombolas e extrativistas. Insiste ainda em negligenciar o descumprimento da ordem constitucional da função social da propriedade, além de criminalizar as lutas dos movimentos sociais.

O conjunto da ópera da atuação estatal é uma das bases da estrutura violenta que impera no espaço agrário brasileiro e contraria as próprias leis, inclusive a Constituição, que reconhece os direitos territoriais das minorias e a necessidade de promoção da reforma agrária como meio de justiça social. Diante disso, apesar e além de direitos escritos, necessita-se de 
uma prática estatal e social que rompa com a lógica colonial da concentração de terras e da subjugação dos direitos territoriais.

De igual modo, as políticas públicas e sociais, essenciais e intrínsecas à promoção do direito a terra, carecem de efetivação sendo indispensáveis à permanência do homem na terra, com condições de viver dignamente.

A permanência dos direitos das minorias sob um processo histórico de invisibilidade e restrição destes grupos a espaços públicos marginalizados da sociedade torna cada vez mais legítima a sua luta. Luta por efetivação e manutenção de direitos. A pacificação das relações no campo só pode ocorrer se de forma igualmente estrutural (em comparação à violência existente) na realidade do campo brasileiro. Não ocorrerá superficialmente ou pela simples existência de letras em papel.

Para tanto a atuação dos Poderes do Estado deve se dar para os fins do Estado Democrático e cumprimento dos seus princípios, abandonando a relativização dos mesmos para proteger classes privilegiadas; modificando o estigma de criminalização e intolerância que há sobre os movimentos sociais e grupos étnico-raciais; agindo de forma a ampliar a democracia para toda a sociedade e não reduzi-la a uma definição de regime político citável em duas linhas. O Estado que se diz democrático precisa incorporar-se democrático. Bem como suas instituições, representantes políticos e cidadãos. Do contrário não se vive democracia alguma.

\section{BIBLIOGRAFIA}

AGAMBEN, Giorgio. A crise infindável como instrumento de poder: uma conversa com Giorgio Agamben, s/p Disponível em <http://blogdaboitempo.com.br/2013/07/17/a-criseinfindavel-como-instrumento-de-poder-uma-conversa-com-giorgio-agamben/> Acesso em: 21 mar. 2016, 10:50.

Estado de Exceção. São Paulo: Boitempo, 2004.

BRASIL. Constituição (1988). Constituição da República Federativa do Brasil. Organização de Alexandre de Moraes. 16.ed. São Paulo: Atlas, 2000.

BRASIL. Lei n. ${ }^{\mathbf{4} .504}$, de 30/11/64. Brasília, 30 de novembro de 1964.

CHAUI, Marilena. Cultura e democracia. In: Crtítica y emancipación: Revista Latinoamericana de Ciencias Sociales. Año 1, no 1 (jun. 2008- ). Buenos Aires: CLACSO, 2008- $\quad . \quad-\quad-\quad$ ISSN $\quad$ 1999-8104. Disponível em 〈http://bibliotecavirtual.clacso.org.ar/ar/libros/secret/CyE/cye3S2a.pdf $>$. Acesso em: 22 mar. 2016, 22:00. 
Paulo: Editora Moderna, 1981.

Dados e informações da Reforma Agrária no Brasil. Disponível em: < http://www.incra.gov.br/reformaagraria $>$. Acesso em: 25 mar. 2016, 11:40.

DUARTE, Nestor. Reforma Agrária. Rio de Janeiro, MEC/SD, 1953.

Amazônia, um bioma mergulhado em conflitos. Relatório Denúncia da Comissão Pastoral da Terra. Articulação das CPT's da Amazônia, 2016.

MARTINS, Jose de Souza. O poder do atraso, Editora Hucitec, São Paulo. 1994.

MEDEIROS, Leonilde Servolo de. Conflitos Fundiários e Violência no Campo. In: Conflitos no Campo Brasil, v. 30, p. 26-30, 2015.

OLIVEIRA. Ariovaldo U. Camponeses, indígenas e quilombolas em luta no campo: a barbárie aumenta. In: Conflitos no Campo, 2015.

ORTEGA, Antônio César. Territórios deprimidos - desafios para as políticas de desenvolvimento rural. Ed. Alinea. 2008.

POLANYI, Karl. (2000), A Grande Transformação: As origens da nossa época. 9a edição, Editora Campus, Rio de Janeiro. Tradução de The Great Transformation, publicado, originalmente por Reinhart \& Company (1944).

Sociedade brasileira: violência e autoritarismo por todos os lados. Entrevista concedida por Marilena Chaui à Revista Cult disponível em: $<$ http://revistacult.uol.com.br/home/2016/02/sociedade-brasileira-violencia-e-autoritarismopor-todos-os-lados/>. Acesso em: 20 mar. 2015, 14:30.

SOUZA FILHO, Carlos Frederico Marés. A Função Social da Terra. Porto Alegre: Fabris, 2003

TÁRREGA, Maria Cristina Vidotte Blanco; RODRIGUES, Bárbara Luiza Ribeiro. A Função Socioambiental da Terra, os Sujeitos de Direitos e as Suas Lutas. In: Conflitos Agrários, seus sujeitos, seus direitos. Goiânia: Editora da PUC Goiás, 2015. P. 93 - 113.

ZIBETTI, Darcy Walmor. Teoria tridimensional da função da terra no espaço rural, econômica, social e ecológica. Ed. Jurua. 2005. 